\title{
24. ELECTRON PARAMAGNETIC RESONANCE STUDY OF THERMAL ALTERATION OF KEROGEN IN DEEP-SEA SEDIMENTS BY BASALTIC SILL INTRUSION
}

\author{
Earl W. Baker and Wen Y. Huang \\ Department of Chemistry, Northeast Louisiana University, Monroe, Louisiana \\ and \\ J. Graham Rankin, J.R. Castaño, J.R. Guinn, and A.N. Fuex \\ Shell Development Company, Bellaire Research Center, Houston, Texas
}

\section{INTRODUCTION}

Site 368 on the Cape Verde Rise was noteworthy for the finding of a basaltic sill of Miocene age intruded into an organic-rich Cretaceous black shale. The sill extended from 957.0 to 970.5 meters and drilling terminated at 984.5 meters in the black shale.

Methane was present above the sill but little or no ethane was present. Approaching the sill, ethane increased but propane and higher hydrocarbons were not detected. The sill was encountered in Core 368-60; Core 368-61 was entirely basalt, and Core 368-62 broke through the sill. Neither gas in large amounts nor liquid hydrocarbons were detected in Core $368-62$ or Core 368-63.

EPR analysis in conjunction with other more conventional measures of maturity of organic materials was performed. We report, here, preliminary results and some modest speculations on the implications of these findings.

\section{EXPERIMENTAL}

\section{Sample Collection}

Samples analyzed from Site 367 consisted of portions of Section 367-19-4, 0-20 cm collected for distribution by the Organic Geochemistry Panel of DSDP and 111 $\mathrm{cm}$ quarter core samples taken from the working half four-months post-cruise. The $20-\mathrm{cm}$ whole section sample is referred to as the OG sample; the other samples from this site are referenced as RK samples. The OG sample was frozen upon collection and remained so until analysis. RK samples were taken to establish the variability of the black shale facies at this site.

At Site 368, an OG sample was taken at Sample 367$63-3,130-150 \mathrm{~cm}$, and frozen in a like manner as the other OG samples. A number of 1-cm quarter-core samples (RK) were taken onboard for organic carbon and carbon:nitrogen analysis shortly after recovery of the cores (see Site 368 chapter, this volume). RK samples were closely spaced $(10-20 \mathrm{~cm}$ near the sill; 60 $\mathrm{cm}$ intervals farther away). Special samples $8 \mathrm{~cm}$ quarter-core) were taken for analysis of the thermal alteration of the organic matter near the sill.These are designated "TA" samples. These samples were collected about 2 days after recovery of the cores but subsequently were kept frozen.
Nine samples of interstitial gas were collected for determination of stable isotope ratios of the light hydrocarbons. These samples (GAS) were taken by puncturing the plastic core liner in the vicinity of a gas bubble and drawing the gas into an evacuated can. Gas chromatographic determination of the components was made onboard. Stable isotope analyses were carried out later using standard methods (see stable isotope section).

\section{Kerogen Preparation}

The kerogen used in the electron paramagnetic resonance (EPR), vitrinite reflectance (VR), and visual kerogen analysis (VKA) was isolated by leaching with hydrochloric and hydrofluoric acids. Details are given in Hood et al (1976).

\section{Pyrolysis-Fluorescence and Pyrolysis-FID Analysis}

These two techniques are used to determine the hydrocarbon potential of the sediment. Details of the method are given in Hood et al. (1976) and Kendrick et al. (this volume).

\section{EPR Spectra}

The purified kerogen sample was placed in a melting point capillary tube and tapped until a packed length of 1 to $2 \mathrm{~cm}$ was obtained. The tube was heat sealed and was placed in a $3 \mathrm{~mm}$ ID $\times 250 \mathrm{~mm}$ quartz tube for EPR analysis.

A Varian model V-4500 spectrometer equipped with audio frequency magnetic field modulation and a phase-sensitive detector was used for EPR measurements. The spectra were recorded by dual cavity technique which allows an accurate measurement of EPR parameters by simultaneously scanning both samples and standard in identical conditions. The reference used in this study was 4-acetamido-2,2,6,6-tetramethyl piperidino-1-oxyl (Eastman 11293). There are three EPR absorption lines in this compound with spacing between adjacent peaks of 15.26 Gauss and a $g$ value of the middle line of 2.00603. This method allows the sample magnetic field to be accurately calibrated by the spacing between the adjacent peaks of the standard (15.26 Gauss). In addition, the $g$ value of the sample can be simply calculated by comparison of the sample to the standard according to the following equation: $H$ $\times g=H^{\prime} \times g^{\prime}$; where $H=$ Gauss reading of absorption line of sample, $g=g$ value of sample, $H^{\prime}=$ Gauss 
reading of absorption line of standard, and $g^{\prime}=g$ value of standard.

The line widths of the EPR spectra were determined by measuring the distance between the two deflection points of the absorption line. In the blank run, using an empty capillary tube, no signal was detected at any gain level of the detector over the magnetic field of interest.

\section{RESULTS}

\section{Electron Paramagnetic Resonance (EPR)}

Most of the kerogen samples from Sites 367 and 368 give very strong EPR signals. The spectroscopic splitting factor, $g$ value, and the peak width are the main concern in these measurements. It has previously been shown that in many cases these parameters reflect the structural transformation of kerogen in geochemical environments (Baker, 1975).

In the present study, two groups of samples have been selected from the black shales of Leg 41 for the purposes of investigating the nature and the effect of geochemical parameters on the chemical structures of kerogen. Samples from Cores 368-59, 368-60, 368-62, and 368-63 (Table 1) were collected within 10 meters above and below the basalt sill. The black shales in this section have been exposed to high temperatures, thus they serve the purpose of studying thermal effects on kerogen. In addition, one sample from a depth of 270 meters (Section 368-27-2) was included for comparison. The second group of samples, which was collected from the Cape Verde Basin, represents the major lithologies of the region between 630 and 780 meters subbottom depth, Site 367.

The spectra for samples of Site 368 are presented in Figure 1 and those for Site 367 in Figure 2. The calculated $g$ values and the peak widths for the two groups of samples are tabulated in Tables 1 and 2, respectively. In order to relate other physical and chemical characteristics of these samples to the results of EPR studies, the reflectance of the kerogen, the depth, total carbon content, $\mathrm{C} / \mathrm{N}$ ratio, FID yield, $\mathrm{D} / \mathrm{P}, \mathrm{PF}$, and Visual Kerogen Analysis (VKA) are also given in Tables 1 and 2 . A positive sign preceding the depth of each sample in Table 1 indicates the distance above the sill and a negative sign the distance below.

In Figure 1, a wide variation in widths, shapes, and intensities is observed in the EPR spectra. Starting as a relatively broad line of 10.23 Gauss in Section 59-2, the EPR spectra become progressively narrower down to 3.25 Gauss in Section 60-3 at $+360 \mathrm{~cm}$ (See Table 1). The $g$ values seem to correlate with the changes of peak widths going from 2.0037 to 2.0030 over the same interval. However, at $243 \mathrm{~cm} \mathrm{(60-3)} \mathrm{above} \mathrm{the} \mathrm{sill,} \mathrm{the}$ trend reverses and finally in the vicinity of the sill the signals flatten and disappear. Below the sill the changes of EPR spectra move in a reverse direction which is evidently caused by the relatively similar heating by the basaltic intrusion. The EPR spectra on both sides of the basaltic sill appear as if they were reflecting each other with the sill as a mirror except that several minor sills above the major sill distort the image. One noticeable difference is the presence of relatively weak signals in samples immediately below the sill (62-3 at -17 and -71 $\mathrm{cm})$. The signals in these two samples are extremely weak, giving a noisy spectrum in which the $g$ value and the peak width measurements are subject to substantial error. The cause of the weak signal is not known but, as is suggested by heat treatment studies discussed later, it is highly probable that these signals are the result of some liquid hydrocarbon driven from the vicinity of the sill which condensed in these sediments.

TABLE 1

EPR Parameters, Visual Analysis, and Reflectivities of Kerogen Isolated From Black Shales and Organic Contents and Hydrocarbon Yields of Black Shales From Site 368

\begin{tabular}{|c|c|c|c|c|c|c|c|c|c|c|c|c|c|}
\hline \multirow{3}{*}{$\begin{array}{l}\text { Sample } \\
\text { (Interval } \\
\text { in } \mathrm{cm} \text { ) }\end{array}$} & \multirow{3}{*}{$\begin{array}{c}\text { Distance } \\
\text { from Sill } \\
(\mathrm{cm})\end{array}$} & \multicolumn{2}{|c|}{ EPR } & \multirow{3}{*}{$\begin{array}{c}\mathrm{R}_{\mathrm{o}} \max \% \mathrm{a} \\
\text { mean } \pm \\
95 \% \text { conf. }\end{array}$} & \multirow{3}{*}{$\begin{array}{l}\text { Org. C } \\
(\% \text { wt) }\end{array}$} & \multirow[b]{3}{*}{$\mathrm{C} / \mathrm{N}$} & \multirow{3}{*}{$\begin{array}{l}\text { FID yield } \\
\text { wt } \% \text { as } \mathrm{HC}\end{array}$} & \multirow[b]{3}{*}{$\mathrm{D} / \mathrm{P}$} & \multirow{3}{*}{$\begin{array}{c}\text { PF } \\
\text { Fluorescence } \\
\text { Units }\end{array}$} & \multirow{3}{*}{$\frac{\text { Visual }}{\mathrm{A}^{\mathrm{c}}}$} & \multirow{3}{*}{$\frac{\text { Kerogen }}{\mathrm{L}^{\mathrm{d}}}$} & \multirow{2}{*}{\multicolumn{2}{|c|}{ Analysis $^{\mathrm{b}}$}} \\
\hline & & & $\begin{array}{c}\text { Peak } \\
\text { Width }\end{array}$ & & & & & & & & & & \\
\hline & & $(\mathrm{g}-2) \times 10^{4}$ & (Gauss) & & & & & & & & & $\mathrm{H}^{\mathrm{e}}$ & $\mathrm{R}^{\mathrm{f}}$ \\
\hline $59-2,0-8$ & +1000 & 37.0 & 10.23 & & & & 0.073 & 0.062 & 2 & & & & \\
\hline $59-3,98-103$ & +737 & 32.9 & 9.46 & & & & 0.011 & 0.306 & 0 & & & & \\
\hline $60-2,55-63$ & +480 & 29.4 & 6.46 & & 0.97 & 10.4 & 0.036 & 0.344 & 0 & & & & \\
\hline $60-3,25-33$ & +360 & 30.1 & 3.25 & & 1.48 & 14.5 & 0.004 & 0.737 & 0 & & & & \\
\hline $60-3,142-150$ & +243 & 33.5 & 19.32 & & & & 0.007 & 3.210 & 0 & & & & \\
\hline $60-4,55-63$ & +188 & & & & 5.09 & 42.7 & 0.009 & 3.684 & 0 & & & & \\
\hline $60-4,110-118$ & +133 & & & & 2.18 & 38.4 & 0.014 & 2.563 & 0 & & & & \\
\hline $60-5,28-36$ & +65 & & & & 3.73 & 18.2 & 0.029 & 4.119 & 3 & & & & \\
\hline $60-5,88-96$ & +5 & & & & 0.20 & 1.1 & 0.004 & 0.466 & 0 & & & & \\
\hline $62-3,18-26$ & -17 & & & $3.33 \pm .23$ & & & 0.004 & 0.457 & 0 & 1 & 1 & 7 & 4 \\
\hline $62-3,72-80$ & -71 & & & $1.95 \pm .09$ & 0.33 & 14.1 & 0.011 & 1.104 & 4 & 1 & 1 & 5 & 5 \\
\hline $62-3,120-128$ & -121 & 30.1 & 5.52 & $0.99 \pm .11$ & & & 0.014 & 0.539 & 0 & 5 & 1 & 2 & 5 \\
\hline $62-4,44-52$ & -193 & 30.4 & 6.69 & $1.42 \pm .30$ & & & 0.263 & 0.110 & 11 & 6 & 1 & 1 & 5 \\
\hline $62-4,118-126$ & -267 & 31.2 & 6.40 & $0.68 \pm .04$ & 11.72 & 19.2 & 1.237 & 0.509 & 105 & 7 & 1 & 2 & 4 \\
\hline $63-1,68-76$ & -367 & 31.4 & 7.34 & ND & & & 1.954 & 0.107 & 75 & & & & \\
\hline $63-2,44-52$ & -493 & 32.5 & 8.36 & $0.48 \pm .05$ & 1.55 & 13.1 & 1.144 & 0.019 & 90 & 7 & 2 & 3 & 3 \\
\hline $63-3,147-150 \mathrm{~g}$ & -741 & 31.2 & 6.12 & $0.44 \pm .03$ & 1.11 & & 0.098 & 0.013 & 3 & 1 & 1 & 7 & 4 \\
\hline $63-4,90-98$ & -839 & 36.3 & 10.28 & $0.50 \pm .05$ & 2.91 & 20.3 & 1.290 & 0.006 & 120 & 7 & 2 & 3 & 3 \\
\hline
\end{tabular}

a Vitrinite reflectance.

${ }^{\mathrm{b}}$ Visual kerogen analysis numerical abundance scale and percentages (by area) $: 1=0-1 \%, 2=1-5 \%, 3=5-10 \%, 4=10-25 \%, 5=25-50 \%, 6=50-75 \%, 7=75-100 \%$.

$\mathrm{c}_{\text {Amorphous. }}$

diptinitic.

$\mathrm{e}_{\text {Humic. }}$

$\mathrm{f}_{\text {Reworked humic and inert. }}$

gOG sample. All other samples in this table are TA. See text under sample collection for sample designation. 

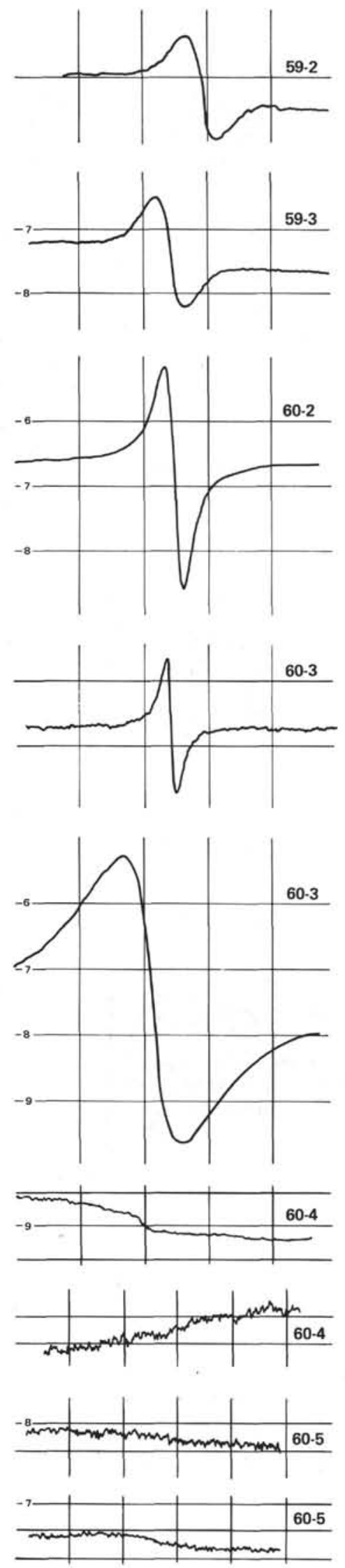
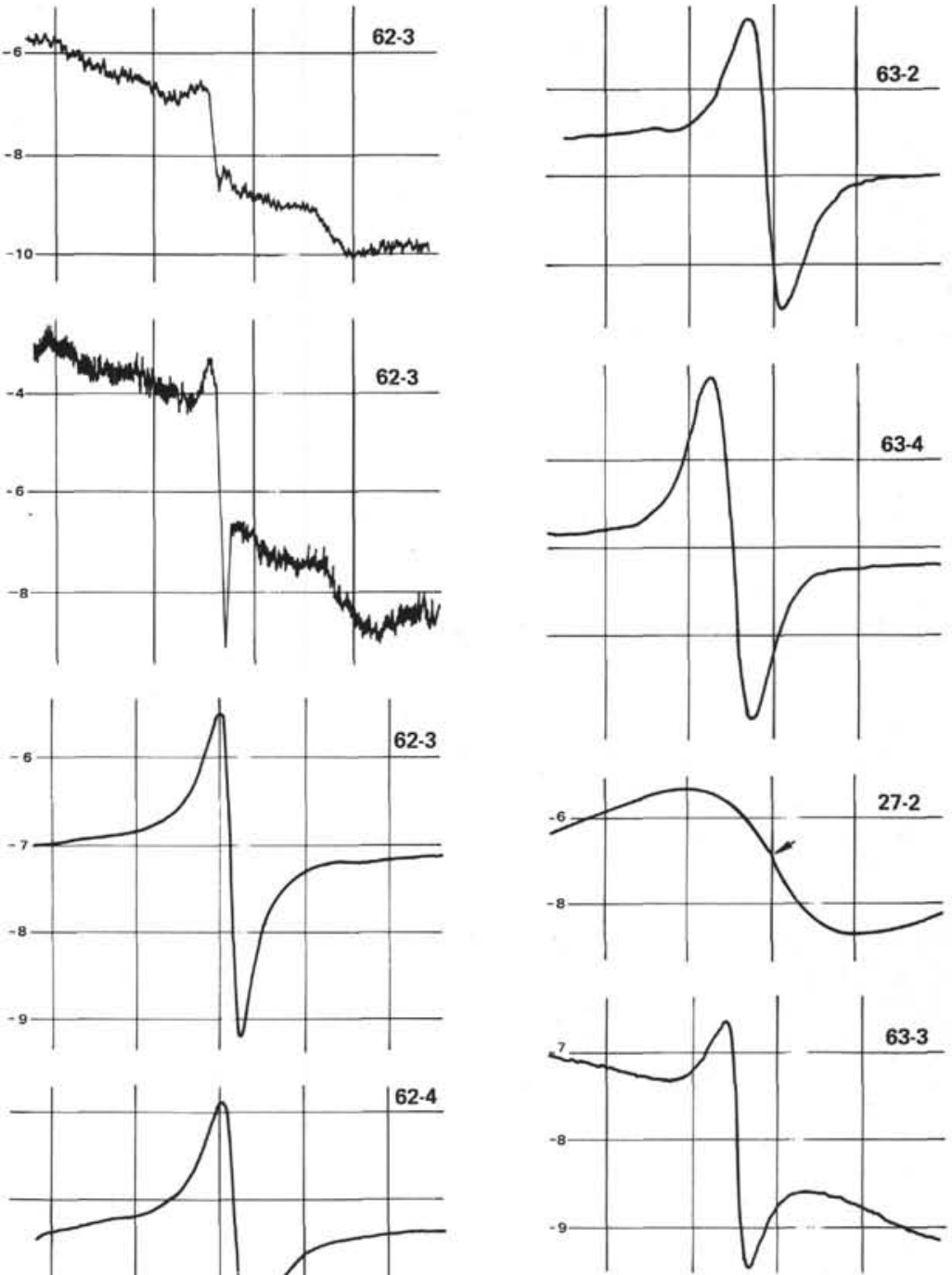

Figure 1. EPR spectra of kerogen from Site 368. For sample identification refer to Table 1. Except for 62-3 and 62-4 which were recorded with 250-Gauss instrument sweep range and for 27-2 which was recorded with a 1000-Gauss range, all other spectra was recorded with 100-Gauss sweep range. 

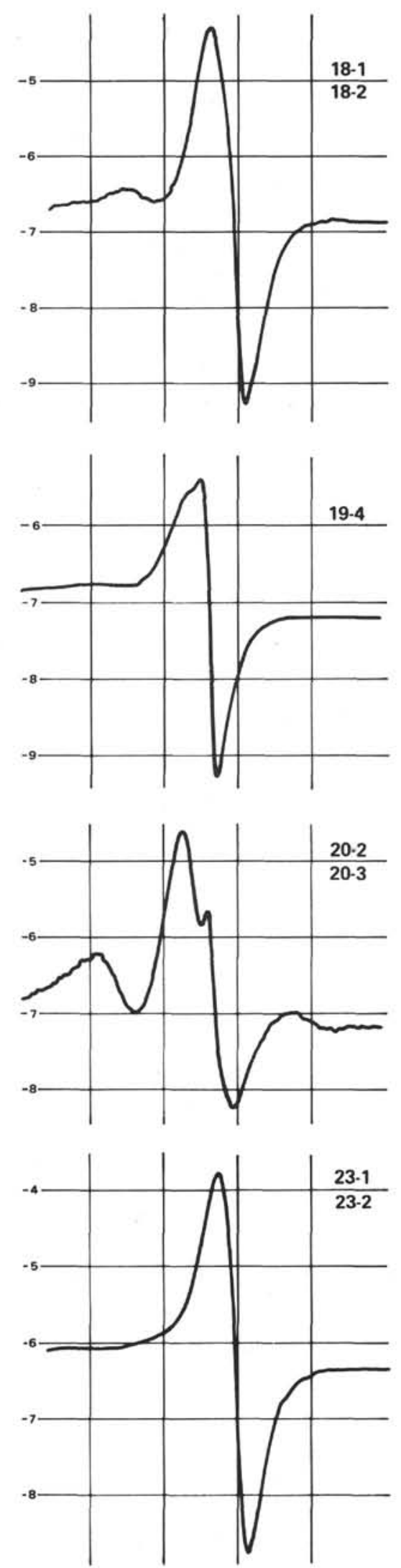

Figure 2. EPR spectra of kerogen from Site 367. For sample identification refer to Table 2. The spectra were recorded with 100-Gauss sweep range.
It is worth noting that kerogen Samples $60-4$ at +133 $\mathrm{cm}$ and $60-5$ at +65 and $+5 \mathrm{~cm}$ behave very differently from other samples when subjected to EPR analysis. These samples absorb a great deal of energy suggesting that inorganic paramagnetic materials may be present.

Sections 63-3 and 27-2 represent kerogen occurring at two quite different depths of burial; however, the EPR spectra of these samples are unique among all of the samples studied. An extremely broad EPR signal is obtained for Section 27-2. The absorption of this sample spans over 400 Gauss, in contrast to the peak widths of the rest of the samples which range from about 4 to 20 Gauss. The depth of this sample is relatively shallow $(270 \mathrm{~m})$ in comparison with the remainder of the samples which were at least 900 meters depth. The sample is light gray and there is no evidence of heating in the surrounding area. Apparently transformation in kerogen structure has not occurred as it did in the remainder of the samples.

In 63-3, two absorption lines are observed. One with a $g$ value of 2.0028 is superimposed on an extremely broad line which is similar to the absorption of 27-2. However, this sample at 980 meters depth is located 741 $\mathrm{cm}$ below the sill. It has a similar color to 27-2 and contains $1.11 \%$ total organic carbon. It is very likely that the thermal stress created by the intrusion has generated the second EPR absorption line. A similar effect has been obtained in the laboratory by heat treatment of 27-2 (see following section).

Three samples from Site 367 (a composite of 18-1 and $18-2 ; 19-4$ at $20-25 \mathrm{~cm}$ and a composite of $20-2$ and $20-$ 3) also exhibited two EPR absorption lines. One with a broader peak width ( 7 to 14 Gauss) is superimposed on a sharper line of lower $g$ value. Because the two absorption lines are only partially resolved, the measurements of $g$ values and peak widths is rendered difficult (see Figure 2). It is interesting to note that the relative intensity of the two absorption lines varies systematically with depth. In the spectra, the narrow line moves toward the lower $g$ values with increasing depth, whereas the broader line either shifts slightly in the opposite direction or remains stationary. As a consequence, the two lines are better resolved at greater depths. Only a single EPR absorption was observed in a composite of 23-1 and 23-2. It has a $g$ value of 2.0032 and peak width of 8.36 Gauss. The presence of the sharp second EPR absorption in the three samples is interesting and probably can be attributed to a different type of material comprising the kerogen.

\section{Heat Treatment of Kerogen}

The kerogen samples collected from Site 368 demonstrated that EPR spectra vary with thermal stress. In order to verify the observed relationship and to obtain some measure of the severity of thermal stress necessary to produce the observed changes, heating experiments of a few selected samples were conducted in the laboratory. The results of these studies are given in Figure 3 and Table 3.

Section 59-2 was the farthest from the diabase sill and presumably the least thermally stressed. Prior to treatment it had a broad EPR absorption line (10.23 Gauss) and high $g$ value (2.00370). The kerogen was sealed in a melting point capillary tube and heated at $250^{\circ} \mathrm{C}$ for $16 \mathrm{hr}$. After treatment, the peak width had 
TABLE 2

EPR Parameters, Visual Analysis, and Reflectivities of Kerogen Isolated From Black Shales and Organic Contents and Hydrocarbon Yields of Black Shales From Site 367

\begin{tabular}{|c|c|c|c|c|c|c|c|c|c|c|c|c|c|}
\hline \multirow{3}{*}{$\begin{array}{l}\text { Sample } \\
\text { (Interval } \\
\text { in } \mathrm{cm} \text { ) }\end{array}$} & \multirow{3}{*}{$\begin{array}{l}\text { Subbottom } \\
\text { Depth } \\
\text { (m) }\end{array}$} & \multicolumn{3}{|c|}{ EPR } & \multirow[b]{3}{*}{$\begin{array}{l}\text { Org. C } \\
(\% w t)\end{array}$} & \multirow[b]{3}{*}{$\mathrm{C} / \mathrm{N}$} & \multirow[b]{3}{*}{$\begin{array}{l}\text { FID yield } \\
\text { wt } \% \text { as } \mathrm{HC}\end{array}$} & \multirow[b]{3}{*}{$\mathrm{D} / \mathrm{P}$} & \multirow{3}{*}{$\begin{array}{c}\text { PF } \\
\text { Fluorescence } \\
\text { Units }\end{array}$} & \multirow{3}{*}{$\frac{\text { Visual }}{\mathrm{A}^{\mathrm{c}}}$} & \multirow{2}{*}{\multicolumn{3}{|c|}{ Kerogen Analysis }} \\
\hline & & \multirow[b]{2}{*}{$(\mathrm{g}-2) \times 10^{4}$} & \multirow{2}{*}{$\begin{array}{l}\text { Peak } \\
\text { Width } \\
\text { (Gauss) }\end{array}$} & \multirow{2}{*}{$\begin{array}{c}\mathrm{R}_{\mathrm{o}} \max \% \mathrm{a} \\
\text { mean } \pm \\
95 \% \text { conf. }\end{array}$} & & & & & & & & & \\
\hline & & & & & & & & & & & $L^{d}$ & $\mathrm{H}^{\mathrm{e}}$ & $\mathrm{R}^{\mathrm{f}}$ \\
\hline $18-1,97-98$ & 637.5 & & 9.90 & $0.19 \pm .02$ & & & 20.384 & 0.019 & 3150 & 7 & 2 & 2 & 2 \\
\hline $18-2,144-145$ & 639.5 & & & & 37.21 & 44.7 & 13.625 & 0.014 & 2700 & & & & \\
\hline $19-1,134-135$ & 649.2 & & & & & & 1.809 & 0.014 & 103 & & & & \\
\hline $19-2,24-25$ & 649.7 & & & & & & 17.384 & 0.014 & 3300 & & & & \\
\hline $19-4,20-25 \mathrm{~g}$ & 652.8 & & 7.02 & $0.18 \pm .01$ & 4.09 & & 2.514 & 0.006 & 240 & 7 & 2 & 2 & 2 \\
\hline $19-4,44-45$ & 653.0 & & & & 18.54 & 34.1 & 13.193 & 0.010 & 3000 & & & & \\
\hline $20-2,7-8$ & 688.1 & & 14.21 & ND & 16.29 & 25.4 & 8.281 & 0.010 & 2550 & 7 & 4 & 2 & 2 \\
\hline $20-3,12-13$ & 689.1 & & & & & & & & 2700 & & & & 2 \\
\hline $21-3,70-71$ & 696.2 & & & & & & 19.972 & 0.008 & 5100 & & & & \\
\hline $22-3,145-146$ & 725.0 & & & & & & 2.201 & 0.007 & 600 & & & & \\
\hline $23-1,32-34$ & 784.3 & 32.1 & 8.36 & $0.30 \pm .03$ & & & 0.951 & 0.007 & 90 & 6 & 2 & 5 & 4 \\
\hline $23-2,83-86$ & 786.3 & & & & & & & & 82 & & & & \\
\hline
\end{tabular}

${ }^{\mathrm{a}}$ Vit rinite reflectance.

${ }^{b}$ Visual kerogen analy sis numerical abundance scale and percentages (by area): $1=0-1 \%, 2=1-5 \%, 3=5-10 \%, 4=10-25 \%, 5=25-50 \%, 6=50-75 \%, 7=75-100 \%$.

$\mathrm{c}_{\text {Amorphous. }}$

dLiptinitic.

${ }^{\mathrm{e}}$ Humic.

$\mathrm{f}_{\text {Reworked humic and inert. }}$

gOG sample. All other samples in this table are RK. See text under sample collection for sample designation.

become 6.35 Gauss and the $g$ value 2.00286 (see Figure 3 and Table 3 ). The result of the heating experiment suggests that thermal stress was responsible for the reduction of the $g$ value and peak width of the EPR absorption lines in samples near the sill at Site 368 .

After being heated at $250^{\circ} \mathrm{C}$ for $22 \mathrm{hr}$, an additional EPR line was observed to be superimposed on the original broad line in Section 27-2. Using 100 Gauss of magnetic sweep range, the EPR spectrum looks remarkably similar to that of Section 63-3, although both the $g$ value and peak width are a little larger (see Tables 1 and 3). Tentatively, these results suggest that a broad EPR absorption (a few hundred Gauss) represents the undisturbed thermally unstressed kerogen. Possibly the generation of "normal" free radicals in kerogen does not occur before certain physicalchemical conditions are severe enough to cause the rupture and/or rearrangement of some chemical bonds in the kerogen structure.

The second sharp EPR line in Sections 19-4 and composite of 18-1 and 18-2 disappeared after the samples were heated at $200^{\circ} \mathrm{C}$ for $24 \mathrm{hr}$. The resulting EPR signals of the two heat-treated samples are similar, varying only by a slight difference in peak width (Table 3). Upon further heating at $320^{\circ} \mathrm{C}$ for $2 \mathrm{hr}$, Section $19-4$ gave a sharper EPR line and the $g$ value was reduced further to 2.00296. In composite of Sections 20-2 and $20-3$, the effect of heating follows a quite different pattern. Instead of the disappearance of the sharp peak as in the previously mentioned two samples, the sharp peak is increased in intensity after $15 \mathrm{hr}$ of heating at $200^{\circ} \mathrm{C}$. Prolonged heating at the same temperature up to $40 \mathrm{hr}$ caused a minor increase in the $\mathrm{g}$ value from 2.0028 to 2.0030 . After further heating at $320^{\circ} \mathrm{C}$ for 2 $\mathrm{hr}$, the EPR spectrum changed abruptly. A broad intense signal appears and overwhelms the previous sharp one. The transformation apparently has not been completed in this treatment because a trace of the sharp EPR signal is still retained in the spectrum (Figure 3). For this sample, some condensed liquid within the capillary tube was seen after the heating. An EPR spectrum of the condensate showed a weak but sharp absorption line (20d in Figure 3).

\section{Stable Isotope Analyses}

Stable carbon $\left(\delta \mathrm{C}^{13}\right)$ and hydrogen $(\delta \mathrm{D})$ isotope analyses on the methane in selected gas samples are given in Table 4. The isotope data are expressed as per mil deviations relative to the PDB standard for carbon and SMOW standard for hydrogen. Methane was separated chromatographically from the rest of the gaseous components prior to its combustion over hot copper oxide in preparation for isotope ratio determination.

The methane $\delta \mathrm{C}^{13}$ values for the Leg 41 sediment gas samples (range: -70.9 to $-54.8 \%$ ) are comparable to those found for similar gases from DSDP Legs 10, 11, $13,14,15,18$, and 19 by Claypool et al., 1973 (range: -89 to $-47 \%$ oo for 65 gas samples). The intrusion of a diabase sill at Site 368 partially metamorphosed at least some of the organic matter in the adjacent shale. This thermal alteration of organic matter is reflected in both the component and isotopic chemistry of the gas samples at $956,972.5$, and 977 meters. In these samples the percent ethane is significantly larger and the methane $\delta \mathrm{C}^{13}$ significantly heavier than gas samples from shallower depths in the same hole, and hence unaffected by heat from the intrusion. These three gases may be interpreted as mixtures of bacterial gas, similar to that found at shallower depths in Hole 368 and thermal gas, which was generated from the organic-rich shale by heat from the igneous intrusion. The thermally derived portion of these gases would contain significant amounts of ethane and higher hydrocarbons, as well as methane which is isotopically heavier compared to bacterial methane. Thus, such a mixture can account for the observed properties of these gases.

The methane $\delta \mathrm{D}$ values for the Leg 41 sediment gases are almost identical to previous measurements on 
E. W. BAKER ET AL.
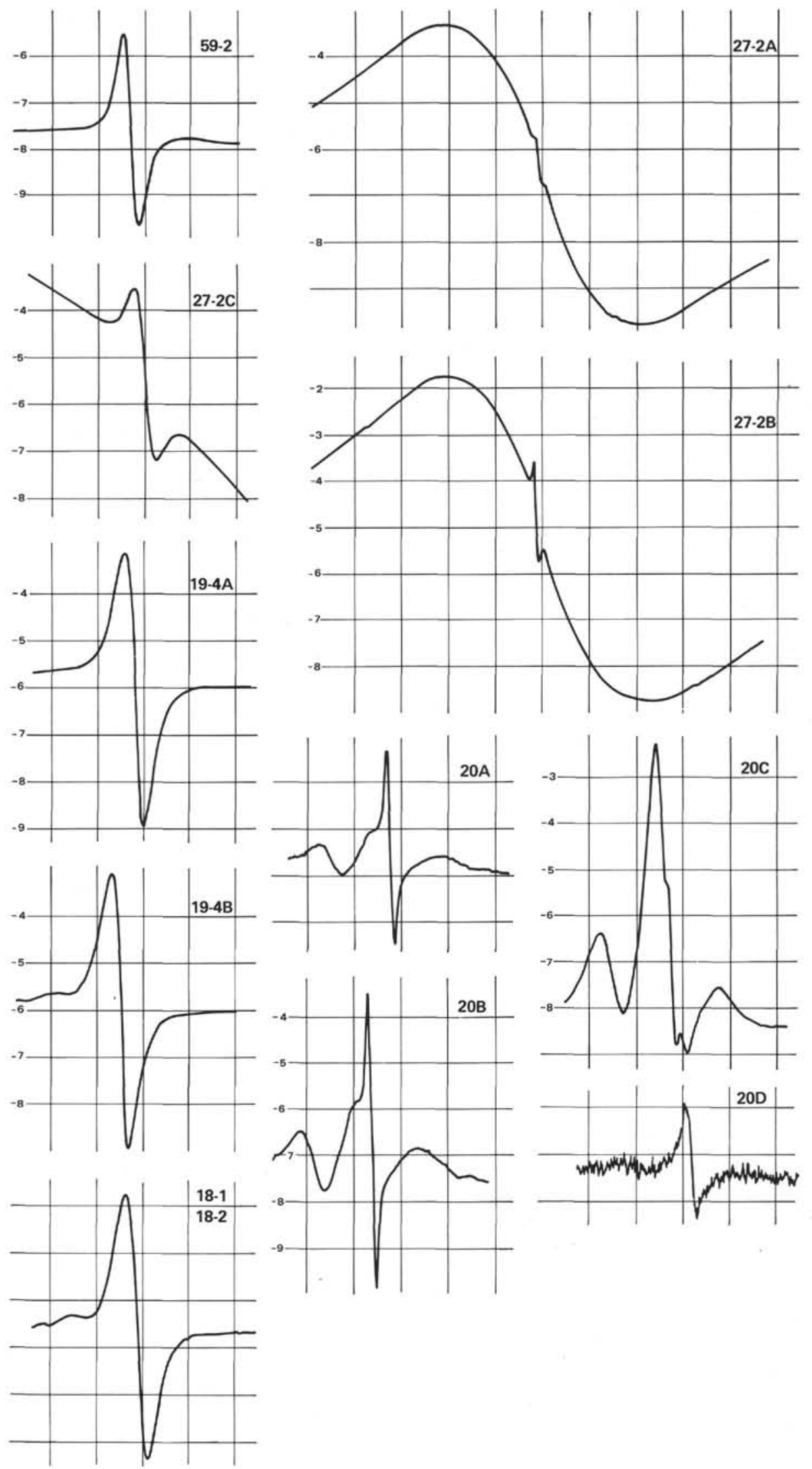

Figure 3. EPR spectra of selected kerogen samples from Sites 367 and 368. The kerogen used for experiments 20A,20B,20C, and 20D is composited of 20-2 and 20-3. For details of heating conditions see Table 3 and text. 
TABLE 3

EPR Parameters of Heat-Treated Kerogen

Samples From Black Shales of Sites 367 and 368

\begin{tabular}{cccc}
\hline Sample & Heating Conditions & $(\mathrm{g}-2) \times 10^{-4 a}$ & $\begin{array}{c}\text { Peak Width } \\
\text { (Gauss) }\end{array}$ \\
\hline $\begin{array}{c}59-2 \\
27-2 \mathrm{~A}\end{array}$ & $250^{\circ} \mathrm{C} 22 \mathrm{hr}$ & 28.6 & 6.35 \\
$\mathrm{~B}$ & $200^{\circ} \mathrm{C} 24 \mathrm{hr}$ & $\overline{31.5}$ & -9.98 \\
$18-1$ & $250^{\circ} \mathrm{C} 16 \mathrm{hr}$ & 34.3 & 10.28 \\
$18-2$ & $200^{\circ} \mathrm{C} 24 \mathrm{hr}$ & & \\
$19-4 \mathrm{~A}$ & $200^{\circ} \mathrm{C} 24 \mathrm{hr}$ & 33.7 & 8.83 \\
$\mathrm{~B}$ & $320^{\circ} \mathrm{C} 2 \mathrm{hr}$ & 29.6 & 7.87 \\
$20-2$ & $200^{\circ} \mathrm{C} 15 \mathrm{hr}$ & 27.9 & 3.26 \\
$20-3 \mathrm{~A}$ & $200^{\circ} \mathrm{C} 40 \mathrm{hr}$ & 29.9 & 3.26 \\
$\mathrm{~B}$ & $320^{\circ} \mathrm{C} 2 \mathrm{hr}$ & $\overline{30.6}$ & $4.15 \mathrm{~b}$ \\
$\mathrm{C}$ & $320^{\circ} \mathrm{C} 2 \mathrm{hr}$ & 30.6 & \\
\hline
\end{tabular}

aHeat treatment times are cummulative.

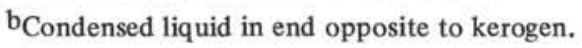

TABLE 4

Isotopic Analyses of Selected Gas Samples

\begin{tabular}{|c|c|c|c|c|c|}
\hline \multirow{2}{*}{$\begin{array}{l}\text { Designation } \\
\text { (DSDP) }\end{array}$} & \multirow{2}{*}{$\begin{array}{c}\text { Depth in } \\
\text { Sediment }(\mathrm{m})\end{array}$} & \multirow{2}{*}{$\begin{array}{l}\text { Percent }{ }^{a} \\
\text { Methane }\end{array}$} & \multirow{2}{*}{$\begin{array}{l}\text { Percent } \\
\text { Ethane }\end{array}$} & \multicolumn{2}{|c|}{ Methane Isotopic Composition } \\
\hline & & & & $8 C^{13}(\mathrm{PDB})$ & $\delta \mathrm{D}$ (SMOW) \\
\hline $367-19-4$ & 649 & 96.5 & 0.06 & $-70.9^{\circ}$ & $-188^{\circ} \%$ \\
\hline $368-25-1$ & 371 & 93.0 & 0.06 & -63.6 & ND \\
\hline $368-39-6$ & 575 & 96.4 & $<0.01$ & -57.0 & -176 \\
\hline $368-60-4$ & 956 & 97.0 & 0.25 & 54.8 & -187 \\
\hline \multicolumn{6}{|c|}{ diabase sill at 957.0 to 970.5 meters in Hole 368} \\
\hline $368-62-4$ & 972.5 & 94.1 & 0.14 & -55.9 & -184 \\
\hline $368-63-2$ & 977 & 95.8 & 0.28 & -55.1 & -181 \\
\hline $369 A-41-3$ & 423 & 82.5 & 0.04 & -69.5 & -179 \\
\hline $369 A-44-2$ & 452 & 69.2 & 0.04 & -68.2 & ND \\
\hline $369 A-47-5$ & 484 & 80.1 & 0.11 & -64.9 & -177 \\
\hline
\end{tabular}

${ }^{\mathrm{a}} \mathrm{CO}_{2}$ contents of these samples ranged from $0.01 \%$ to $0.7 \%$, with the balance of the samples being mainly undifferentiated "air."

DSDP gas samples. Lyon (1974) measured methane hydrogen isotopic compositions of eight DSDP sediment gases from the Cariaco Basin (Leg 15, Site 147) and obtained values between -183 and $-173^{\circ} \%$, which he considered essentially identical within experimental error. The $\delta \mathrm{D}$ values of the sediment thus appear to be independent of both geographic locality and subbottom depth. This may be the result of a relatively constant fractionation associated with the bacterial generation of methane, plus a fairly uniform concentration of deuterium in marine organic matter and/or interstitial sediment water. On the other hand, the uniformity of deuterium concentration in DSDP methanes might be indicative of a postgeneration isotopic equilibration with interstitial water, which can be assumed to have a uniform composition, close to SMOW. However, a state of isotopic equilibrium has apparently not been reached, as calculated equilibrium temperatures differ by about $40^{\circ} \mathrm{C}$ from the estimated sediment temperatures (Lyon, 1974). It is also possible that the very narrow range of methane $\delta \mathrm{D}$ values is simply fortuitous.

\section{CHN Analyses, Pyrolysis Studies, and Vitrinite Reflectance Measurements}

The samples from Site 367 (Table 2) are rich in organic matter with high hydrocarbon potential but are quite immature. There is considerable variation within the sequence ( $4 \%$ to $37 \%$ organic carbon; $1 \%$ to $20 \%$ FID yield). The richest organic content is near the top (Core 367-18) of the black shale facies becoming less rich near the bottom (Core 367-23). Visual kerogen analysis indicates an abundance of amorphous kerogen which is in keeping with higher pyrolysis FID results. Vitrinite reflectance measurements indicate that all samples analyzed at this site have reflectivities typical of that found in the lignite stage of coal.

The samples near the basaltic intrusion in Site 368 (Table 1) from 957-970 meters subbottom show considerable thermal alteration. Vitrinite reflectance values as high as $3.3 \%$ and texture, as seen through the microscope, indicate "coking" of the sediments by the sill. Pyrolysis-FID yields are very low as is the percent organic carbon. Farther away from the sill (about $2 \mathrm{~m}$ ) pyrolysis-FID yields remain low although organic carbon values are high. This may be the result of localized generation of hydrocarbons, as noted by the higher distillable/pyrolyzable ratios $(D / P)$, with subsequent expulsion to nearby sediments.

A profile of the organic carbon results of the $\mathrm{CHN}$ analysis of RK samples near the sill is given in Figure 4. These results are taken from Site 368 chapter (this volume).

\section{DISCUSSION}

The $g$ values observed in the kerogen samples of the present work are, except for a few unusual cases which will be discussed separately, generally low (2.00292.0037) and similar to the EPR spectra reported for petroleum asphaltene, suggesting typical aromatic systems with delocalized electrons. The narrowing of line widths and the decrease of $g$ value as the sample locations approach the heat pocket caused by the sill are consistent with the results of earlier studies on kerogen in natural environments (Hwang and Pusey, 1973), asphaltene (Yen et al., 1962), and coal (Austen et al., 1965). The unusual broading of EPR spectral lines similar to that seen in the sample about $250 \mathrm{~cm}$ above the sill was reported by Baker (1975), but the obliteration of EPR spectra as observed in the samples immediately above and below the sill has not been previously reported. The study of petroleum asphaltene by Yen et al. (1962) shows that heating up to $460^{\circ} \mathrm{C}$ only causes narrowing of line widths and increases rather than decreases spin concentrations. Total elimination of free radicals did not occur in coal maceral up to $750^{\circ} \mathrm{C}$ (Austen et al., 1965). It is not known whether the extreme heat supplied by the intrusion alone has destroyed the aromatic structures of the kerogen which are presumably the free radical sites or whether the presence of inorganic minerals is partially responsible for the disappearance of the free radicals.

In several cases atypical EPR spectra were observed in these samples. In one case, a previously unreported spectral set consisting of two absorptions was discovered and we now discuss these atypical sets.

One of the supposed transient forms in the diagenesis of kerogen is the geminal formation of an aromatictype free radical. In Section 27-2 such a transition may have been observed. The germane portion of the spectrum (Figure 1, 27-2) is seen at the point where the curvature reverses from convex to concave. Careful 


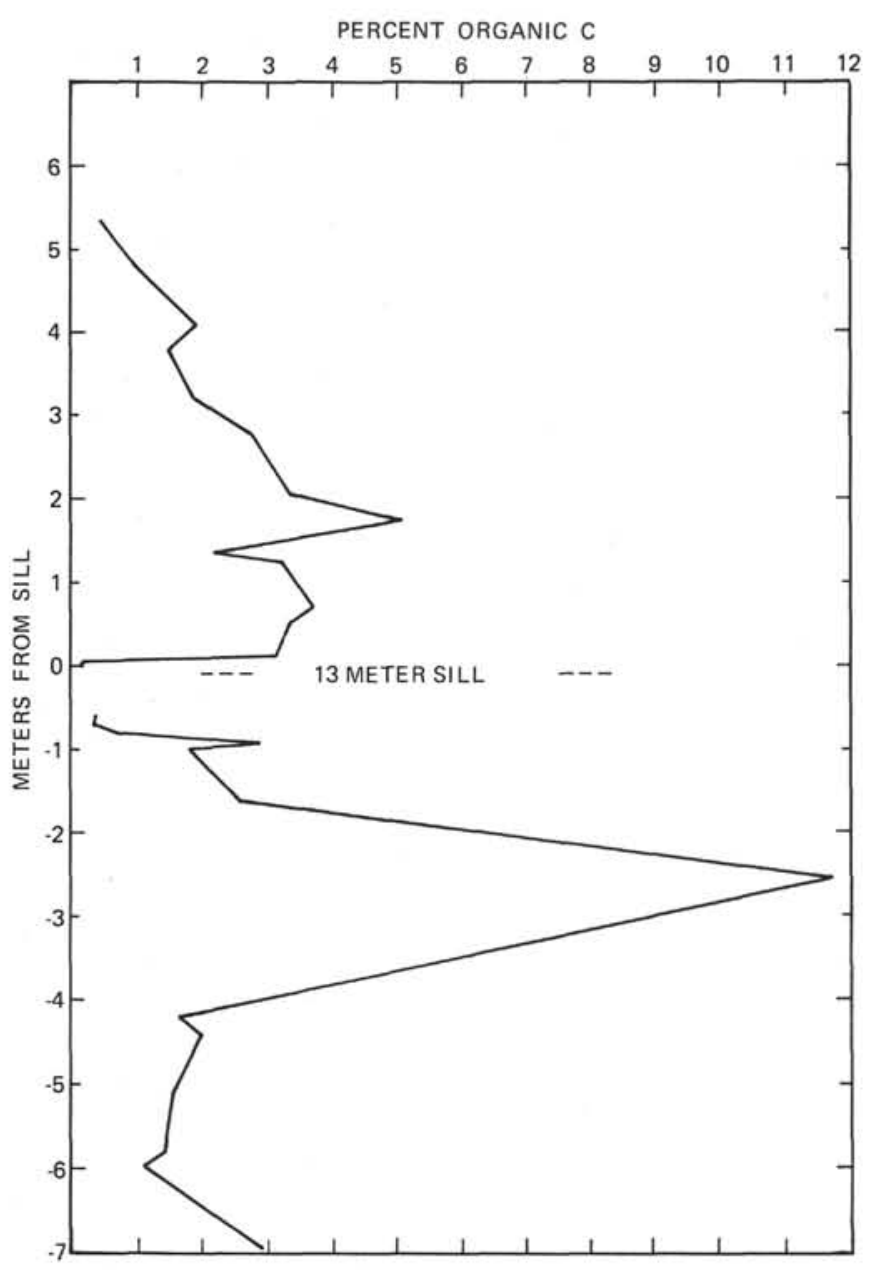

Figure 4. Total organic carbon plotted against the distance from the sill.

perusal shows that imposed on the broad sweeping band is a tiny signal with a $g$ value nominally that of a "normal" aromatic radical. Interestingly, progressive heat treatment of this kerogen produces progressive enlargement of the tiny signal into a major one (Figure $3,27-2$ A, B, C). These experiments suggest that the generation of a "normal" free radical has been observed and that in the native kerogen, incipient radical formation had just been initiated.

It has been proposed that narrowing of band width of EPR spectra is related to the maximum temperature of exposure (Hwang and Pusey, 1973). In the sample sequence $59-2,59-3,60-2$, and $60-3$ we observed a natural illustration of this effect (Figure 1, first four spectra). In concert with the narrowing of the band width, the $g$ value decreased. Laboratory heating experiments confirmed the interpretation of these observations. Section 59-2, upon modest treatment, was converted such that its spectrum very closely resembled 60-2 (compare Figure 3, 59-2 with Figure 1, 60-2 and Table $3,59-2$ with Table $1,60-2$ ). Laboratory heating apparently duplicated the effect of the heating by the intrusion.

In the case previously discussed, $27-2$, the "normal" aromatic EPR absorption was seen superimposed on a very broad band possibly not of organic origin. In
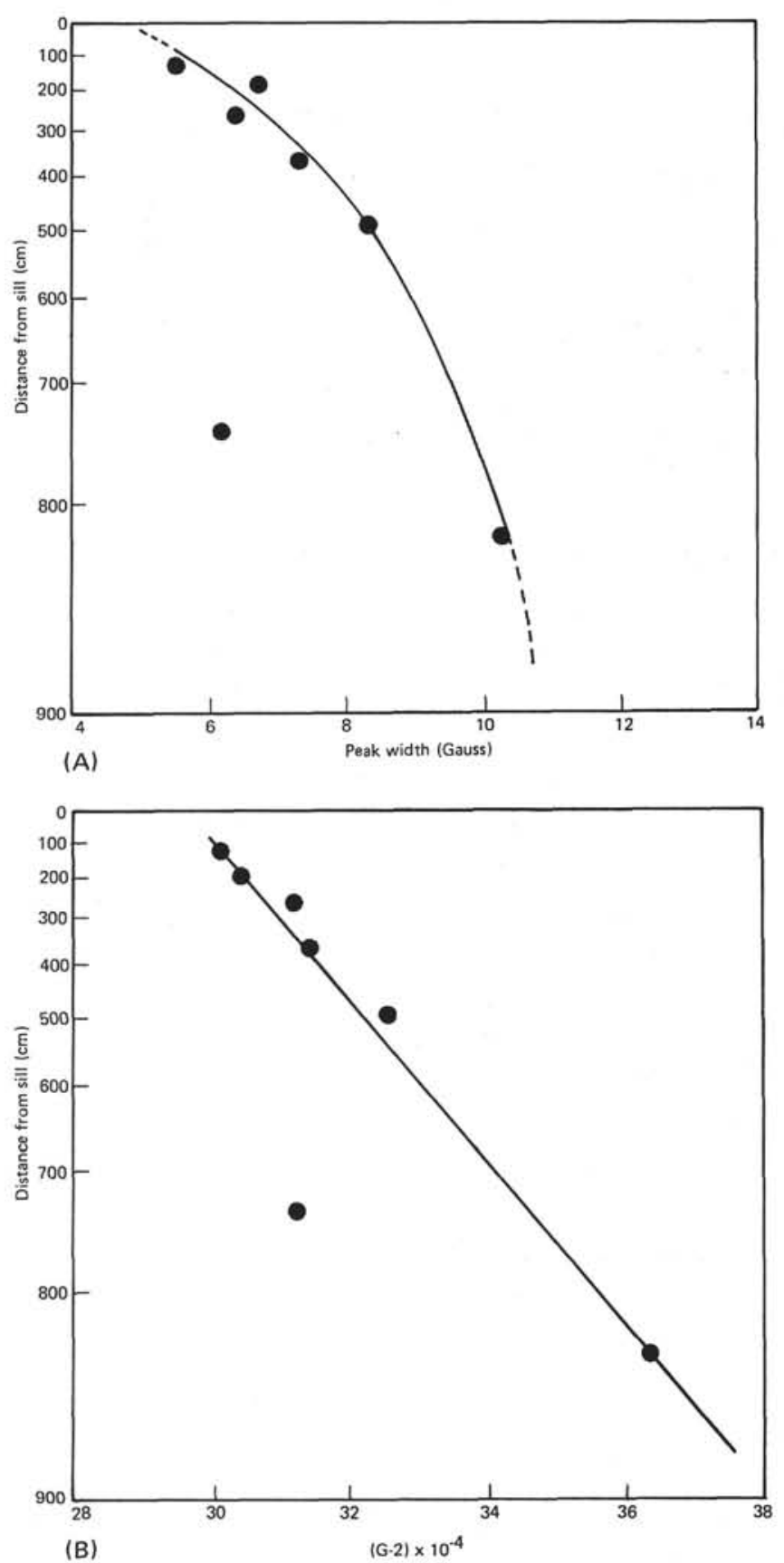

Figure 5. (A) EPR peak width (Gauss) of kerogen from immediately below sill (Site 368) plotted against log of distance from sill. $(B) G$ value $\left[(\mathrm{g}-2) \times 10^{-4}\right]$ of kerogen from immediately below sill (Site 368) plotted against log of distance from sill.

contrast, a group of kerogens was observed with two absorptions in the region normally allocated to organic radicals. Such two banded spectra are illustrated in Figure 2. The narrow absorption band in these samples deserves note, because of the heat labile nature of the kerogen component represented by it (compare Figure 3, 20-2 a and b, 18-1 with Figure 2, 20-2, and 18-1). The contrast with the broader band which is probably a "normal" aromatic-free radical absorption is evident, since after limited heat treatment the signal is no longer 
observed. These signals then most likely represent a different type of organic structure with a $g$ value lower than the "normal" aromatic kerogen signal. Possibly they contain heteroatoms and are less aromatized than mature kerogens and thus lack the stability of the free radical normally associated with such structures.

\section{Variation in EPR Parameters and Other Characteristics} of Kerogen and Shale in the Vicinity of the Intrusion

A plot of $g$ value versus log of the distance from the sill gives a good fit (Figure 5), except in the case of 63-3 which appears to be a different type of kerogen (Table 2 , VKA). If the observed $g$ value is a measure of the integrated time-temperature exposure of the kerogen (shale) and the temperature falls exponentially with distance then such a plot is not unexpected.

Interestingly, a similar plot using band width instead of $g$ value versus log distance gives a nonlinear best fit. Again, Section 63-3 falls far off the line. Since the factors making up the band width are very complex, no simple explanation for the observed trend can be offered. It is, however, felt that the linear case presented by Hwang and Pusey is probably a narrow segment of a similar curve (Hwang and Pusey, 1973).

Bostick (1970) concluded that the effect on vitrinite reflectance for sills less than 10 meters thick was confined to an interval about equal to the sill thickness above and below the intrusion. The thermal effect seen at this site, as indicated by EPR parameters, vitrinite reflectance, pyrolysis fluorescence, and pyrolysis-FID, decreased rapidly and is minimal greater than 6 meters below the sill. As mentioned earlier some minor sills above the major sill complicate the "mirror image" effect for samples above the sill.

\section{ACKNOWLEDGMENTS}

The present work was supported by National Science Foundation, Grant GA-43359X and DES-74-12438 AO1.
The authors are indebted to Dr. R.E. Smith for technical assistance with the EPR spectrometer. They also thank Dr. T. Strom of Mobil Research and Development for his suggestion of using 4-acetamido-2, 2, 6, 6-tetramethyl piperidino-1-oxyl as a reference for EPR measurement, and Dr. S.E. Palmer for help which was greatly needed.

\section{REFERENCES}

Austen, D.E.G., Ingram, D.J.E., Given, P.H., Binder, C.R., and Hill, L.W., 1965. Electron spin resonance study of pure macerals: Adv. Chem. Ser., no. 55, p. 344-359.

Baker, E.W., 1975. Electron paramagnetic resonance study of kerogen samples: Conference on Fossil Fuel Chemistry and Energy. July 22-26, 1975, Laramie, Wyoming.

Bostick, N.H., 1970. Thermal alteration of clastic organic particles (phytoclasts) as an indicator of contact and burial metamorphism in sedimentary rocks: Ph.D. Dissertation, Stanford Univ., Palo Alto, Calif., p. 220.

Claypool, G.E., Presley, B.J., and Kaplan, I.R., 1973. Gas analysis in sediment samples from Legs $10,11,13,14,15$, 18, and 19. In Initial Reports of the Deep Sea Drilling Project, Volume 19: Washington (U.S. Government Printing Office), p. 879-884.

Hood, A., Castaño, J.R., and Kendrick, J.W., 1976. Petroleum-generating potential and thermal history of DSDP Leg 38 sediments. In Initial Reports of the Deep Sea Drilling Project, Volume 38: Washington (U.S. Government Printing Office, p. 801.

Hwang, P.T.R. and Pusey, W.C., 1973. Process for determining hydrocarbon maturity using electron spin resonance: United States Patent 3,740,641.

Lyon, G.L., 1974. Isotopic analysis of gas from the Cariaco Trench sediments. In Kaplan, I.R. (Ed.), Natural gases in marine sediments: New York (Plenum Press), p. 91-96.

Yen, T.F., Erdman, J.G., and Saraceno, A.J., 1962. Investigation of the nature of free radicals in petroleum asphaltenes and related substances by electron spin resonance: Anal. Chem., v. 34, p. 694-700. 